Revista Latino-americana de

Ambiente Construído \& Sustentabilidade

ISSN 2675-7524 / v. 1, n. 1 (2020)

Técnicas compensatórias e planejamento citadino: dispositivos implantados no campus da UFSCar, São Carlos/SP

Rodrigo Augusto Guerra Mestrando, PPGEU-UFSCar, Brasil rodrigoaguerra@gmail.com

Luciana Márcia Gonçalves

Professora Doutora, UFSCar, Brasil lucianamg@ufscar.br 
Revista Latino-americana de

Ambiente Construído \& Sustentabilidade

ISSN 2675-7524 / v. 1, n. 1 (2020)

\section{INTRODUÇÃO}

A relação do ser humano, e consequentemente da cidade, com a água passou por diferentes momentos no decorrer dos anos, desde seu apreço, no início da vida nômade (pela agricultura e higiene possibilitadas), até sua rejeição, no desenvolvimento dos primeiros sistemas de evacuação de águas integradamente ao desenvolvimento urbano nas Idades Antiga e Média (BAPTISTA; NASCIMENTO e BARRAUD, 2011). A separação através da canalização surgiu juntamente com os princípios higienistas, que associaram a presença da água a algo patogênico e fétido, o que, na realidade, relacionava-se à pouca manutenção dos sistemas de evacuação de águas pluviais e esgoto, que acarretou em seu desuso, deixando-as escorrendo pelas ruas (BAPTISTA; NASCIMENTO e BARRAUD, 2011).

No século XIX, com o aumento exponencial da população urbana, a precária infraestrutura de controle das águas urbanas favoreceu o alastramento de epidemias pela Europa, mudando a relação do urbanismo e as águas citadinas, que passou a pregar seu escoamento mais rápido possível (BAPTISTA; NASCIMENTO e BARRAUD, 2011). O aumento da população urbana continuou durante o século XX, e em 2010 o Brasil já chegava a 84,36\% da população vivendo em cidades (IBGE, 2010).

Conforme mais pessoas habitam a cidade, mais urbanizada e impermeável ela tornase, devido ao atual padrão de ocupação, provocando mais inundações (Figura 1) e, por conseguinte, aumentando o número de pessoas atingidas, um cenário visível praticamente no mundo todo, porém com ênfase em países em desenvolvimento, como o Brasil (JHA; BLOCH e LAMOND, 2012).

Figura 1: Balanço hídrico antes e depois da urbanização

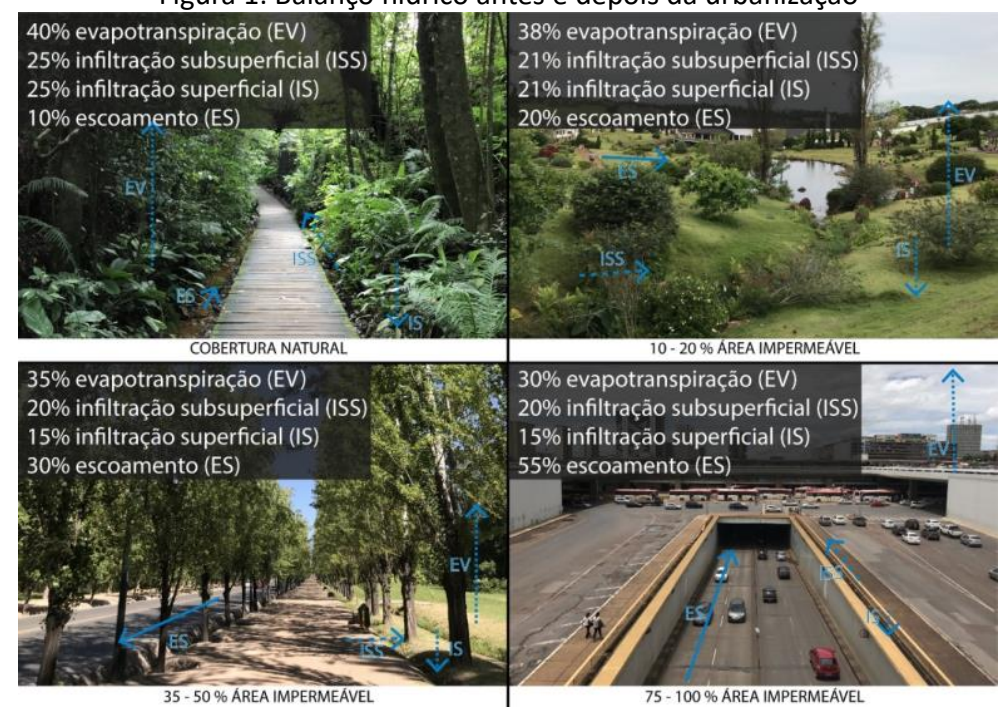

Fonte: PRINCE GEORGE'S COUNTY, 1999; BAPTISTA, 2015, elaborado pelo autor, 2020.

A partir da alta taxa de urbanização e do aumento populacional urbano, são necessários novos tratamentos do espaço da cidade. Na legislação brasileira, o Estatuto da Cidade, Lei $\mathrm{N}^{\circ} 10.257$, de 10 de julho de 2001, regulamenta os artigos 182 e 183 da Constituição Federal de 1988, e nele é apontado o Plano Diretor de Desenvolvimento Urbano (PDU) como o principal instrumento para o ordenamento territorial citadino. O planejamento municipal a 
partir do PDU e do zoneamento define o uso e ocupação dos espaços de modo a garantir o desenvolvimento dos cidadãos e o cumprimento da função social da cidade. A lei aponta normas a serem observadas pelos gestores municipais quanto à ordenação territorial, elaboração e execução das políticas urbanas (BARROS; CARVALHO e MONTANDON, 2010). Em 2003, com a criação do Ministério das Cidades - atualmente extinto -, houve maior apoio às cidades quanto a consolidação de modelos que englobassem saneamento, habitação e mobilidade urbana, com menções à cidade sustentável, apoiando a implementação da lei do Estatuto, de modo a facilitar o enfrentamento de questões sociais, ambientais e econômicas que afetam a vida de muitos brasileiros (FERNANDES, 2010).

As consequências do descontrole da drenagem urbana atingem principalmente áreas localizadas à jusante (sentido de fluxo do curso d'água), pois é onde chegam rapidamente, através de tubulações, grande volume de água - não infiltrada ou evaporada nas montantes (áreas mais acima do rio) - e poluição, causando impactos que atingem tanto o meio ambiente e populações locais quanto o poder público (TUCCI, 2002)(OLIVEIRA, 2018).

Dentre as consequências da alteração do ciclo hidrológico geradas pelo modelo de ocupação predominante no Brasil, pode-se citar a cadeia de acontecimentos em que (OLIVEIRA, 2018):

- A taxa de infiltração da água no solo é reduzida pela impermeabilização, de modo a diminuir o abastecimento de aquíferos e aumentar a quantidade e velocidade de seu escoamento superficial;

- A não retenção da água por vegetações reduz a evapotranspiração natural, processo essencial para o balanço hídrico, auxiliado por folhagens e solos;

- Todo o volume de água escoado varre forçosamente a poluição superficial e favorece a sedimentação do solo.

Apesar das principais notícias sobre problemas quanto à drenagem urbana serem provenientes de grandes aglomerados urbanos, a questão também atinge cidades de pequeno e médio portes. Com o passar do tempo, o sistema tradicional de drenagem pluvial tem se demonstrado ineficaz no combate a enchentes e inundações, influenciando na qualidade de vida dos habitantes e até dos cursos d'água que recebem a água com poluentes que lava a área urbana (VENTURA; VAZ FILHO e GONÇALVES, 2019). A partir desta situação, novas posturas quanto a técnicas e abordagens alternativas ao sistema clássico de drenagem pluvial urbana estão em estudo e são empregadas, como:

- $\quad$ Técnicas Compensatórias (TCs) ou Best Management Practices (BMPs);

- Desenvolvimento de Baixo Impacto (Low Impact Development - LID);

- Desenho Urbano Sensível à Água (Water Sensitive Urban Design - WSUD).

Tais abordagens possuem em comum o apontamento da importância da manutenção das áreas permeáveis dentro do solo urbano, visando tornar o sistema mais próximo do processo natural, em que o ciclo hidrológico é respeitado e incentivado. São apontados desenhos urbanos, elementos vegetais e estruturas para auxílio da infiltração da água no solo e garantia do escoamento superficial de baixa velocidade (UNIVERSITY OF ARKANSAS COMMUNITY DESIGN CENTER, 2010). 
Entretanto, para implementação destas abordagens que favorecem o curso d'água pluvial na superfície são requeridos espaços urbanos disponíveis (lotes, glebas, áreas verdes etc.), visto que não seria utilizado o sistema de tubos enterrados atuais. $O$ acesso à terra urbana atualmente está diretamente relacionado ao preço desta (MARICATO, 2010), tornando a espacialização de projetos e planos tema obrigatório em PDUs, principalmente por meio do zoneamento. Portanto, o manejo da água pluvial urbana precisa ser integrado ao ordenamento territorial.

As abordagens alternativas desenvolvidas e testadas devem ser discutidas nos PDUs, de modo que suas aplicabilidades atinjam a cidade real. Agentes responsáveis pela produção do espaço urbano, incluindo gestores e moradores da cidade, precisam compreender a necessidade de integração das águas pluviais aos planos urbanos desde os princípios norteadores do desenvolvimento urbano.

Diante da dificuldade de implementação de abordagens alternativas de drenagem pluvial urbana e manejos integrados nas obras de urbanização, verifica-se a necessidade de uma aproximação mais eficaz entre PDUs e demais planos urbanos, ou seja, além de objetivarem as mesmas premissas de redução de impactos, devem tratar de diretrizes projetuais que nem mesmos planos específicos de drenagem urbana têm apresentado. $O$ objetivo da pesquisa de mestrado da qual este artigo derivou foca no desenvolvimento de estratégias para inclusão das abordagens alternativas da drenagem urbana aos PDUs.

As águas pluviais urbanas são precipitações ocorridas no interior do perímetro urbano ou que, de alguma outra forma, atravessam seu limite e passam a fazer parte da área urbanizada. Sua gestão deve ser cuidadosa e sempre levada em consideração, pois a chuva faz parte do ciclo hidrológico natural e, apesar da rejeição de sua presença no ambiente citadino, incentivada pelos higienistas, ela por ali passará.

As abordagens não tradicionais de drenagem pluvial surgiram a partir da busca pela manutenção do escoamento, da infiltração e da evapotranspiração da água em ambientes urbanos.

Algumas das consequências relacionadas à água pluvial pós-urbanização de uma bacia hidrográfica nos moldes de cidade atuais, onde há grandes áreas desvegetadas e impermeabilizadas, segundo Baptista; Nascimento e Barraud (2011) e Prince George's County (1999), são:

1a Etapa - no local:

- Impermeabilização do solo diminui a quantidade de água que infiltra no solo que tornaria o solo úmido e abasteceria possíveis lençóis subterrâneos;

- Retirada da vegetação diminui a quantidade de água que sofre evapotranspiração - mecanismo vegetal natural que aumentaria a umidade do ar;

- $\quad$ Ainda ocorre a evaporação natural de uma pequena parcela da água.

2a Etapa - no caminho:

- Grande volume da água que permaneceria no local tem como única opção gravitacional escoar conforme a declividade local;

- $\quad$ Rugosidade diminuta permite que a água atinja maiores velocidades; 
- Vazão da água duplamente aumentada (volume escoado e velocidade de escoamento);

- $\quad$ Arraste de sedimentos pela alta velocidade, causando erosão;

3a Etapa - no destino:

- $\quad$ Sedimentos anteriormente arrastados são depositados no fundo de cursos d'água, causando assoreamento;

- Partículas anteriormente arrastadas são levadas a locais onde não pertenciam, podendo causar alteração na qualidade da água e desequilíbrio ambiental.

Levando em conta este processo, as abordagens visam a quebra do circuito no início e no percurso da água pluvial, possibilitando melhores condições também nas áreas à jusante.

\subsection{Técnicas Compensatórias (TCs) ou Best Management Practices (BMPs)}

Desenvolvidas na América do Norte com o nome de Best Management Practices, nos anos de 1970, são elementos que compensam a grande quantidade de água pluvial escoada pela impermeabilização do solo urbano através da detenção e infiltração. O controle do volume e da velocidade do escoamento superficial tende a diminuir a probabilidade da ocorrência de inundações e possibilitar melhor qualidade da água escoada. Por se tratar de diversas técnicas, torna-se viável a combinação de várias em um mesmo empreendimento, além da integração a diferentes ambientes urbanos ou naturais (TUCCI, 1995; BAPTISTA; NASCIMENTO e BARRAUD, 2011).

Sua aplicabilidade também propicia multifuncionalidade, através de usos em períodos que não estão preenchidas com água, podendo servir de estacionamento, áreas esportivas, sistemas viários, passeios e parques lineares, integrando-a ao espaço citadino (OLIVEIRA, 2018; BAPTISTA; GONÇALVES e RIBEIRO, 2016).

Segundo Baptista; Nascimento e Barraud (2011), as TCs possuem duas grandes divisões: as não estruturais e as estruturais. As primeiras incluem o retardo do escoamento a partir de camadas superficiais de maior rugosidade e incentivos legislativos e educacionais quanto a diminuição do escoamento de água pluvial ao sistema de drenagem. Já as estruturais, possuem dois métodos de classificação: segundo o princípio básico de funcionamento da TC (infiltração, retenção ou ambos) ou segundo a posição de implantação do dispositivo (pontual, linear ou em bacias).

$\mathrm{Na}$ aplicação de cada TC, é preciso levar em consideração alguns aspectos físicos, hidrológicos, urbanísticos e de infraestruturas locais, como:

- Topografia;

- Caminho e destino das águas pluviais;

- Análise do solo (capacidade de infiltração de água, estabilidade e nível das águas subterrâneas);

- $\quad$ Presença permanente ou temporária de água no sistema;

- $\quad$ Espaço disponível para implantação;

- Inclinação e desenho do telhado (quando aplicado na cobertura ou esta for 


\author{
desconectada do sistema tradicional); \\ - Análise e localização das redes públicas já existentes no subsolo.
}

Sendo assim, há certas restrições e características de grande importância que devem ser consideradas para de cada TC, visando seu melhor funcionamento.

Por tratar-se de estruturas que têm como principal foco o manejo de águas pluviais, é preciso que sempre existam extravasores, pois o dimensionamento define uma chuva de projeto que ora ou outra será extrapolada; e há a possibilidade de entupimento por folhas ou até resíduos sólidos que poderia causar impactos não previstos. Outros pontos importantes são: qualidade da água, dependendo da permeabilidade do solo e dos poluentes presentes na água escoada, esta pode poluir águas subterrâneas; como a água não é tratada, não deve permanecer estagnada por mais do que 24 horas, pois pode favorecer o desenvolvimento de organismos de vetores de doenças; outras infraestruturas existentes podem impedir a construção da TC; e, por fim, deve-se conhecer a distância do lençol freático ao fundo da TC e a permeabilidade saturada do solo (PRINCE GEORGE'S COUNTY, 1999; BAPTISTA; NASCIMENTO e BARRAUD, 2011; RIGHETTO, 2009). Sendo assim, os conjuntos de TCs devem ser estudados quanto a seus funcionamentos-bases, de modo a facilitar o direcionamento quando desenvolvendo as diretrizes.

\title{
2 OBJETIVO
}

Neste artigo, demonstra-se, por meio da descrição de TCs construídas e submetidas a situações em escala real, as possibilidades de integração e compensação dos dispositivos e seus comportamentos em ambientes reais. Serão analisadas as características e demandas das TCs construídas no campus da Universidade Federal de São Carlos (UFSCar), em São Carlos/SP, referenciando-se, sempre, à Figura 2 para apontamento de cada TC abordada.

Paiva (2016) tratou da divulgação e conscientização dos transeuntes quanto às TCs construídas, através de materiais gráficos implantados próximos a cada sistema.

Este artigo objetiva o levantamento e organização de critérios de avaliação de experiencia inédita de pesquisa sobre TCs, a partir de estruturas implantadas em escala real no campus da UFSCar, resultantes de pesquisas integradas do Grupo de Estudos em Sistemas Hídricos Urbanos (G-HIDRO), da UFSCar de São Carlos/SP, com auxílio financeiro pelo projeto de Manejo de Águas Pluviais Urbanas do FINEP/BRUM, e da Prefeitura do campus da UFSCar de São Carlos. São descritos e discutidos seus resultados, principalmente, no âmbito urbanístico, de modo a colaborar com a pesquisa de mestrado da qual faz parte. Apesar de não terem sido implantados todos os tipos de TCs, em seus trabalhos específicos estudou-se as necessidades da integração urbanística, e do atendimento à funcionalidade hidrológica, condições sanitárias e ambientais das experiencias. 
Revista Latino-americana de

Ambiente Construído \& Sustentabilidade

ISSN 2675-7524 / v. 1, n. 1 (2020)

Figura 2: TCs construídas no campus da UFSCar, microbacia experimental na Área Norte, em São Carlos/SP

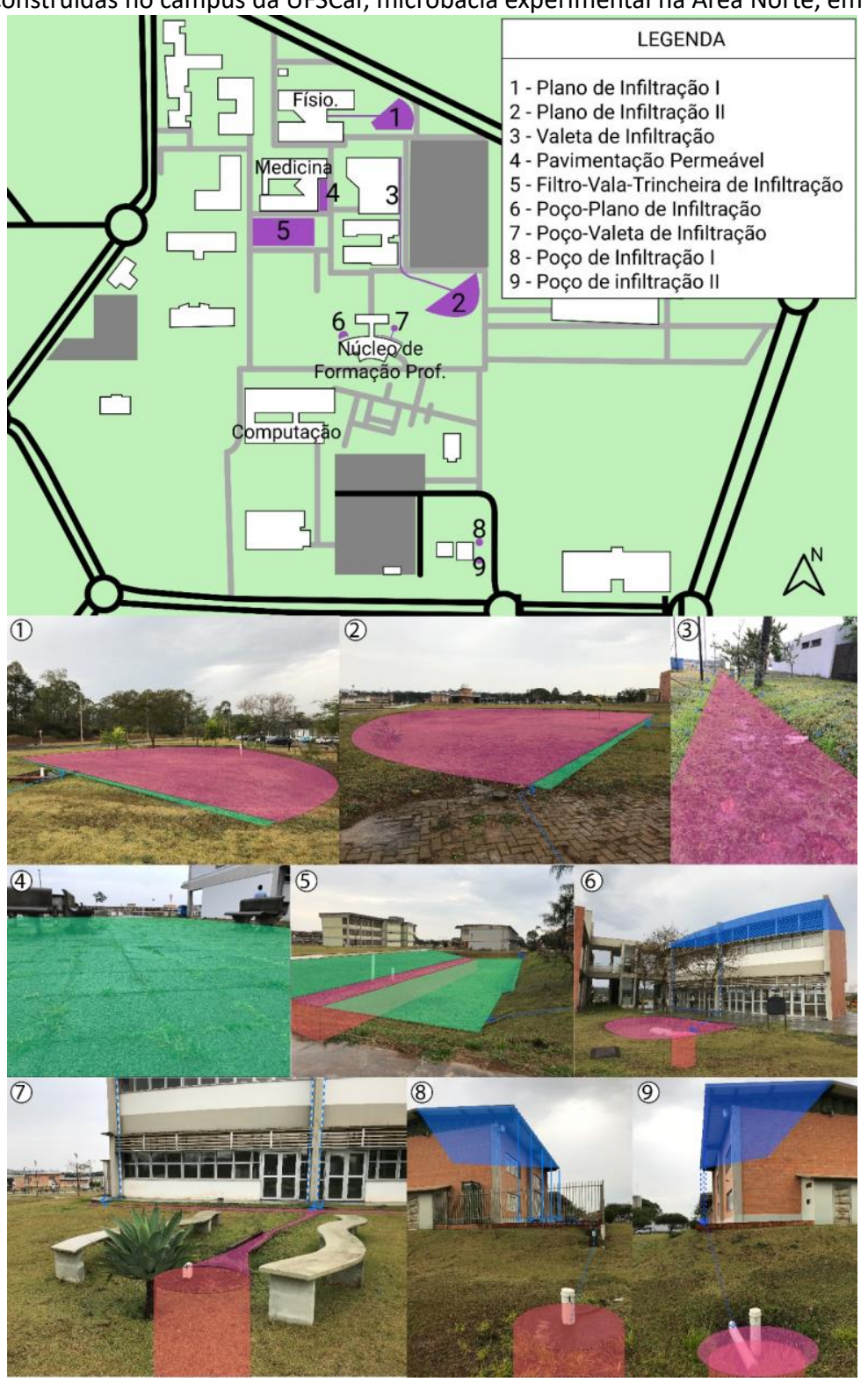

Fonte: Elaborada pelo autor, 2020.

\section{MÉTODOS}

Neste artigo, foram analisados os dispositivos compensatórios da drenagem urbana construídos em escala real no campus da UFSCar em São Carlos/SP, os quais foram operados e mantidos pelo G-HIDRO - alguns por mais de 10 anos. Seguiu-se a seguinte sequência de desenvolvimento:

- Revisão bibliográfica do histórico do planejamento urbano relacionado ao manejo de águas pluviais urbanas, bem como suas consequências diretas e indiretas; seguida da revisão bibliográfica de técnicas compensatórias na drenagem pluvial urbana e abordagens alternativas relacionadas à drenagem sustentável, permitindo a análise de conceitos, condições e necessidades de cada TC (disponibilidade de espaço, tipo de solo e capacidade de 
armazenamento como principais características);

- Por meio de visita técnica às construções, com acompanhamento de professores e pesquisadores do G-HIDRO que participaram da instalação de parte dos dispositivos, foram resgatados objetivos e impasses do histórico das instalações. A consulta objetiva aos professores e pesquisadores participantes do desenvolvimento e implantação das TCs, permitiram apontamentos, descrições e informações mais detalhados da realização, bem como dificuldades enfrentadas;

- Realização de busca bibliográfica em artigos, teses e dissertações do Programa de Pós-Graduação em Engenharia Urbana da UFSCar de São Carlos/SP, nos quais foram apresentados cálculos de projeto, critérios de escolha do local das TCS implantadas foram realizadas as caracterizações dos dispositivos e estudos dos resultados obtidos nas análises realizadas após a implantação;

- Outra importante fase do levantamento foi a visitação às TCs em momentos de pluviosidade, para observação do caminho da água e comportamento paisagístico nos dispositivos;

- Mapeamento e seleção de imagens do acervo fotográfico G-HIDRO com descritivo dos dispositivos implantados na microbacia experimental da Área Norte do campus;

- Foi realizada a análise dos aspectos urbanísticos, ambientais, sanitários e hidrológicos das TCs, como maior foco no primeiro, como integração, espaço utilizado e multifuncionalidade;

- $\quad$ Por fim, foi desenvolvido quadro com informações comparativas entre as TCs implantadas, no âmbito urbanístico e espacial.

\section{RESULTADOS}

\subsection{Técnicas Compensatórias UFSCar}

\subsubsection{Trincheiras de Infiltração e Detenção}

Integrantes ao grupo de TCs lineares, apresentam maior dimensão no sentido longitudinal, quando comparada a suas larguras e profundidades (no máximo um metro cada). Sua principal função é de redução do escoamento de águas pluviais através do armazenamento, mas também é capaz de remover diversas bactérias e poluentes, diminuindo o risco de contaminação de lençóis subterrâneos (BAPTISTA; NASCIMENTO e BARRAUD, 2011; SOUZA et al., 2018; URBONAS e STAHRE, 1993).

O sistema recebe água pluvial perpendicularmente ao seu comprimento, podendo ser por escoamento superficial ou por tubulações conectadas diretamente ao seu interior, preenchido com materiais granulares graúdos, como pedra de mão, seixos e britas, de modo a possibilitar o armazenamento de água nos espaços não preenchidos. Por ter sua escavação similar a drenos do sistema tradicional, é de fácil execução. Diferentemente das trincheiras de detenção, que devem ser revestidas com materiais impermeáveis, as de infiltração devem ser 
revestidas com mantas geotêxtis, para evitar a passagem de materiais finos que possam colmatar a estrutura. A evacuação da água, como nas bacias, pode ser através de tubulações redutoras, no caso de detenção, ou infiltrando no solo, no de infiltração (BAPTISTA; NASCIMENTO e BARRAUD, 2011).

Baptista; Nascimento e Barraud (2011) citam três principais inconvenientes de seu uso:

- Manutenções devem ser periódicas, para controle da colmatação, que ocorre primeiro no fundo e laterais do sistema. Como nas TCs de bacias, existem as preventivas (limpeza dos poços, filtros e órgãos de descarga e conservação das áreas verdes) e as corretivas (substituição ou somente limpeza dos materiais interiores e da superfície do sistema quando for detectado funcionamento inadequado);

- Existência de restrições quanto à implantação em áreas de grandes declividades - é conveniente o uso de divisórias internas (geomembranas em conjunto com manta geotêxtil ou somente muretas feitas de materiais pouco ou nada permeáveis, visando melhor aproveitamento do volume de armazenamento;

- Os fundos de trincheiras de infiltração devem distar, ao menos, um metro vertical até o nível do lençol subterrâneo, evitando sua fácil contaminação - em áreas de recarga direta de aquíferos, recomenda-se sua não utilização).

Apesar de serem escavadas e preenchidas com pedras, permite-se, após o fechamento com a manta protetora, cobri-las com terra e vegetação, evitando espécies que perdem suas folhagens ou que tenham raízes que ofereçam risco de perfurarem a manta.

O G-HIDRO, Lucas (2011) como responsável, realizou a construção, no campus da UFSCar, em São Carlos/SP, de um sistema chamado filtro-vala-trincheira (FVT) de infiltração (item 5 da Figura 2), o qual recebe água pluvial da desconexão do sistema tradicional de drenagem pluvial do telhado do edifício do Departamento de Medicina (BAPTISTA, 2015). Assim que cai no telhado, a água escoa até as calhas e é direcionada, perpendicularmente, a uma canaleta de distribuição, que faz com que a água desça uniformemente até a trincheira.

Já dentro da TC, a água percorre três etapas:

- $\quad$ Filtro - caminho gramado de baixa inclinação, para retenção de sedimentos;

- Vala - caminho gramado de maior inclinação, para retenção de sedimentos e armazenamento complementar a trincheira, quando em pluviosidades mais intensas;

- Trincheira - espaço escavado preenchido com brita 3 na área de armazenamento da água escoada, envolto em manta geotêxtil, coberto com areia grossa e seixo rolado.

\subsubsection{Valas, Valetas e Planos de Detenção e Infiltração}

São TCs especializadas como simples depressões, ou seja, escavações menos profundas do que bacias, podendo ser projetadas em áreas (planos) ou lineares (valas ou valetas - vala de menor dimensão). As de detenção propiciam o armazenamento temporário, enquanto as de infiltração permitem o armazenamento e a permeabilidade no solo. Entretanto, ambos 
tipos viabilizam a evapotranspiração quando vegetados. Há, ainda, a possibilidade de funcionamento como canais direcionadores das águas pluviais, de modo a infiltrar, reter sedimentos, remover poluições e auxiliar na redução da velocidade de escoamento, de modo a amortecer as vazões (BAPTISTA; NASCIMENTO e BARRAUD, 2011; BUTLER e DAVIES, 2000).

Por serem depressões mais suaves, são de fácil construção e possibilitam a integração ao meio no qual estão inseridas, viabilizando intervenções paisagísticas que agreguem valor estético e de conforto. Deve-se tomar cuidado quanto à visibilidade do sistema, de modo que os transeuntes entendam seu funcionamento e não ocorram quedas ou acidentes. Baptista; Nascimento e Barraud (2011) citam como os principais inconvenientes de suas aplicações:

- Restrições quanto a aplicação em áreas com fortes declives - diminui a deposição de sedimentos, necessitam de compartimentalização e podem provocar erosões;

- Se de infiltração, devem distar, verticalmente, ao menos um metro do lençol freático (como as trincheiras de infiltração);

- Quando ao lado de vias, posicioná-las em nível inferior e com paredes impermeáveis, de modo a evitar o movimento horizontal da água para debaixo do leito da via;

- Se mal executadas, pode ocorrer o acúmulo de água - propiciando implicações sanitárias;

- Deve-se evitar árvores que perdem muitas folhas juntas ao sistema, pois pode causar sua obstrução;

- Manutenção periódica - preventiva (jardinagem e limpeza regular) e corretiva (quando de infiltração, substituição da terra vegetal em caso de colmatação do solo; quando de detenção, substituição dos orifícios e canalizações deteriorados).

O G-HIDRO realizou a construção, no campus da UFSCar, em São Carlos/SP, de dois planos de infiltração e uma valeta gramada. O primeiro plano de infiltração construído (PI1) teve Tecedor (2014) como responsável (item 1 da Figura 2), e contou com a desconexão da drenagem das águas pluviais proveniente do telhado do edifício do Departamento de Fisioterapia. A técnica foi escolhida devido à disponibilidade de área (conforme Plano Diretor do campus) e os aspectos físicos, urbanísticos, sanitários, ambientais, socioeconômicos e de infraestrutura locais favoráveis permitiram sua implantação. O sistema do PI1 conta com a desconexão da água escoada pelo telhado do edifício do Departamento de Fisioterapia, interceptando tubulações no solo e direcionando para um vertedouro $120^{\circ}$ com caixa de areia e um distribuidor de vazão com britas, para escoamento mais homogêneo na superfície da TC.

O segundo plano de infiltração (PI2), bem como as demais TCs construídas no campus pelo G-HIDRO, tiveram suas execuções quase simultaneamente, nos anos de 2012 e 2013 (item 2 da Figura 2). O dispositivo recebe água escoada da área de estacionamento à jusante e contém, similarmente ao primeiro, um vertedouro com caixa de areia e um distribuidor de vazão preenchido com britas.

Em ambos planos de infiltração houve o tratamento paisagístico elaborado por Pereira (2016), que considerou as TCs como espaços que agregam valor estético ao ambiente no qual 
são inseridas. Foram utilizadas espécies vegetais que suportam períodos de seca e de água acumulada, e que trazem singularidade, identidade e destaque ao ponto referencial urbanístico do projeto.

Houve também, no campus, a implantação de uma valeta de infiltração, que teve Felipe (2014) e Shinzato (2015) como responsáveis (item 3 da Figura 2). O sistema foi chamado de canal gramado, segundo nomenclatura de Cambridge City Council (2009), e permitiu o estudo da retenção de sedimentos e poluição pela presença da grama no caminho de escoamento da água pluvial. A TC recebe água pluvial da desconexão da cobertura do edifício da Gerontologia, e serve como escoamento do exutório do PI1, à montante, quando este for sobrecarregado.

\subsubsection{Pavimentos Permeáveis Dotados de Estruturas de Detenção e Infiltração}

O principal ponto a ser questionado quanto à alteração do ciclo hidrológico é a enorme quantidade de área impermeável gerada pelo modelo de assentamento urbano comumente desenvolvido - grande uso do concreto e asfalto nas superfícies. Considerando o cenário urbano, cita-se que áreas de estacionamento para veículos chegam a somar $30 \%$ da área total de uma bacia de drenagem, áreas que acabam não sendo passíveis de infiltração da água no solo (BAPTISTA; NASCIMENTO e BARRAUD, 2011; PARRA, 2016; PEREIRA, 2016). Neste contexto, surgem as seguintes TCs lineares:

- $\quad$ Pavimentos permeáveis - permitem a passagem da água para o solo, realizando a infiltração;

- Pavimentos porosos - fazem a detenção temporária da água, armazenando-a;

- Pavimentos porosos e permeáveis - detém a água e a faz infiltrar no solo aos poucos.

São TCs que possibilitam a infiltração da água pluvial no solo, aumentando a recarga de lençóis subterrâneos, bem como a redução do volume escoado e amortecimento de vazões, dependendo da tipologia escolhida para aplicação em projeto.

O asfalto poroso e os blocos de concreto vazados são alguns exemplos de pavimentos permeáveis. Há ainda os chamados semipermeáveis, como paralelepípedos, calçamentos poliédricos ou blocos de concreto intertravados, que permitem uma pequena taxa de infiltração.

Seu uso é bastante versátil, podendo ser utilizado em praças, parques, estacionamentos, ruas e até avenidas de alto fluxo de automóveis, gerando conforto e segurança, já que reduz as poças d'água e a possibilidade de aquaplanagem. Há indicativos de que o concreto permeável seja bastante utilizado no desenvolvimento urbano, visando acessibilidade a todos, visto que possibilita o fluxo de pessoas com deficiências mantendo áreas em que ocorra a infiltração da água pluvial no solo (MOTA, 2014; PREFEITURA MUNICIPAL DE MESQUITA, 2018; BAPTISTA; NASCIMENTO e BARRAUD, 2011).

Alguns inconvenientes da utilização de pavimentos permeáveis são, segundo Baptista; Nascimento; Barraud (2011) e Righetto (2009):

- Risco de colmatação - na superfície do pavimento (poros superiores são bloqueados por sedimentações) e no corpo do pavimento (poros interiores são entupidos, também por sedimentações); 
- Deve-se manter a distância vertical mínima de um metro até o lençol freático, de modo a diminuir a chance de poluição do mesmo (como outras TCs de infiltração);

- Trata-se de um revestimento frágil a grandes esforços de cisalhamento, como em áreas de manobra ou curvas;

- Manutenções devem ser feitas frequentemente para assegurar o funcionamento hidráulico do pavimento (inclui jateamento ou varredura a jato).

Vale lembrar que quanto maior os poros e maior velocidade de fluxo da via onde é aplicado o pavimento, mais lento o processo de colmatação.

No campus da UFSCar, em São Carlos/SP, há dois modelos de pavimentos porosos ou permeáveis implantados. $\mathrm{O}$ mais comum deles está presente em várias áreas de passeio para pedestres e estacionamentos, que é o bloco de concreto intertravado (Figura 3), cujo responsável por sua implantação é a Prefeitura do campus. Entretanto, suas manutenções não têm sido feitas adequadamente, e há casos em que se comportam como impermeáveis (PARRA, 2016).

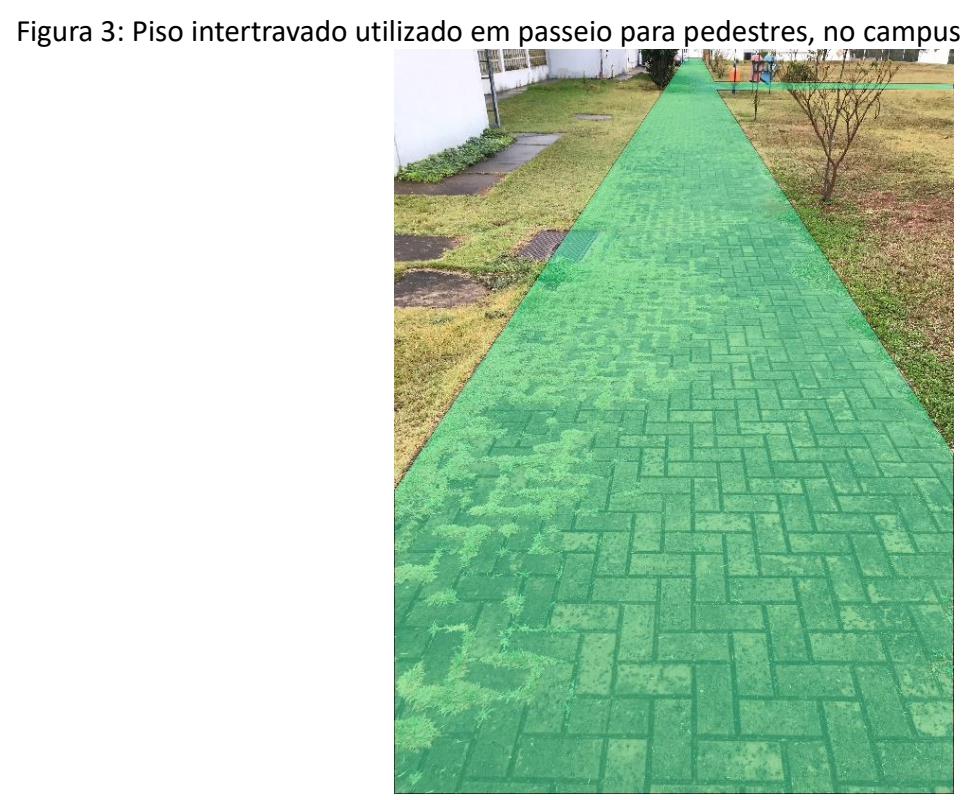

Fonte: Elaborada pelo autor, 2020.

Outro uso de TC existente no campus é o piso de concreto drenante, implantado por iniciativa do Departamento de Medicina e do Escritório de Desenvolvimento Físico, ambos da UFSCar. A TC instalada em um local de encontros e descanso (item 4 da Figura 2) foi analisada por Parra (2016), que constatou, no ano de 2015, a existência de rachaduras, desníveis e vegetações nos seus poros, condições que geram mal funcionamento hidráulico no sistema. No ano de 2019 , os mesmos apontamentos foram verificados no local.

\subsubsection{Poços}

São TCs pontuais de infiltração utilizadas para armazenamento de águas pluviais em um pequeno espaço superficial, já que possuem maior dimensão em sua profundidade, 
propiciando melhor integração ao espaço urbano. Permitem ser implantados em locais cujas camadas superiores do solo são pouco permeáveis, pois a zona de infiltração está nas laterais e fundos dos poços. Suas principais funções são de redução das vazões de pico e recarga de lençóis subterrâneos (BAPTISTA; NASCIMENTO e BARRAUD, 2011; ANGELINI SOBRINHA, 2012; REIS; OLIVEIRA e SALES, 2008).

Os poços podem ser vazios ou preenchidos com materiais porosos - mínimo $30 \%$ de porosidade, como britas, por exemplo -, tendo, estes, menores capacidades de armazenamento. Há também diferenciações quanto ao recebimento das águas pluviais, que podem adentrar via escoamento superficial ou diretamente ao interior do volume através de uma rede (BAPTISTA; NASCIMENTO e BARRAUD, 2011; FERREIRA, 2016).

Alguns inconvenientes de suas implantações, segundo Baptista; Nascimento e Barraud (2011) e Ferreira (2016), são:

- Não é aconselhável evacuar as águas armazenadas através da injeção no lençol subterrâneo (inclusive é proibida em alguns países) - quando existente, alocar dispositivos de pré-tratamento da água, de modo a evitar poluição ou contaminação direta;

- Deixar um metro vertical entre o fundo do sistema e o nível do lençol freático (como todo dispositivo de infiltração), visando reduzir o risco de contaminação ou poluição;

- Manter distância de elementos de fundação de edificações, raízes e encostas redes urbanas no subsolo não são tidas como empecilhos;

- Deixar a estrutura visível e conscientizar transeuntes, evitando a deposição de rejeitos sob o sistema;

- É recomendada a disposição de uma caixa de decantação anterior ao poço, com função de reter matérias em suspensão;

- $\quad$ Prever o acesso para inspeções - regularmente e após chuvas intensas;

- Considerar o tempo de drenagem máximo de 72 horas;

- Necessidade de manutenção regular para evitar a colmatação - limpeza de calhas direcionadoras até o sistema; substituição de filtros; remoção de sedimentos e resíduos.

No campus da UFSCar, em São Carlos/SP, há dois poços de infiltração implantados pelo G-HIDRO, com Ferreira (2016) como responsável. Ambos utilizaram o mesmo número de anéis de concreto em sua construção. O poço de infiltração I possui características similares aos implantados no município (item 8 da Figura 2), respeitando cálculos dimensionais da legislação municipal. 0 dispositivo recebe água pluvial escoada da desconexão da cobertura Norte do Laboratório de Polímeros.

O segundo poço de infiltração foi desenvolvido pelo G-HIDRO, de modo a aumentar a infiltração e a vida útil do sistema (item 9 da Figura 2). 0 dispositivo coleta a água pluvial escoada pela cobertura Sul do mesmo edifício que o primeiro poço. Por possuir brita em sua cobertura e nas laterais, é capaz de armazenar maior volume de água, além de ter sido constatado maior volume infiltrado, quando em comparação ao poço I.

Há também dois outros poços construídos no campus que foram integrados a outra 
TC, e ambos captam a água escoada do telhado Núcleo de Formação de Professores - cada um capta metade da cobertura. O primeiro deles teve Baptista (2015) como responsável e integrava plano e poço de infiltração (item 6 da Figura 2). Com intuito de utilizar-se da TC para criar um espaço de convivência e lazer que poderia ser apropriado pelos usuários do edifício próximo, houve a escolha do plano de infiltração. Segundo Ferreira et al. (2013), este é inundado quando ocorrem altos índices pluviométricos, enquanto o poço de infiltração é utilizado para escoamento em chuvas mais frequentes.

Uma característica destacada nas TCs implantadas no campus é que, na maioria delas, há o incentivo ao uso do espaço como área de convivência para os transeuntes, demonstrando a possibilidade de interação e multifuncionalidade dos dispositivos aplicados em meio urbano construído.

O segundo poço teve Angelini Sobrinha (2012) como responsável, e houve a mescla de valeta e poço de infiltração (item 7 da Figura 2). A valeta de infiltração tem função de direcionamento da água coletada pelas calhas da cobertura até a superfície do poço, também auxiliando na retenção de sedimentos. Assim como o primeiro, esta TC também incentiva a apropriação do local como espaço de convivência e lazer.

O poço tem seu núcleo estrutural em anéis de concreto perfurado, com revestimento de manta geotêxtil e assentamento de tijolos furados e outra manta geotêxtil nas laterais para conter o solo que poderia entraria no sistema e aumentar a área de infiltração. Na base foram posicionadas britas 3 e um bloco de concreto. A grade de metal, envolta em manta geotêxtil e a camada de areia grossa e brita 3 colocadas à cima do poço permitem a remoção de sedimentos e entrada de água no sistema. Também foi implantado um vertedouro 90 o no caminho da água, antes de chegar à superfície do poço. Visando sua apropriação, também foram desenvolvidas as ideias de identificação e melhoria das condições paisagísticas locais com a implantação de bancos de formas orgânicas e vegetações similares às dos planos de infiltração (PEREIRA, 2016; ANGELINI SOBRINHA, 2012).

\subsection{Análises Espaciais}

No campus da UFSCar em São Carlos/SP, mesmo existindo considerável disponibilidade de espaços livres (conforme o Plano Diretor do Campus), há expectativa de expansão nos edifícios existentes e implantação de novas construções. Portanto, a consulta à Prefeitura do campus quanto a locais livres no momento do projeto e nas estratégias de expansão dos edifícios foi extremamente necessária.

A análise da metragem de área superficial necessária para a implantação dos dispositivos gerou a Tabela 1. Não foram incluídos dispositivos com função de transporte da água pluvial, somente aqueles com função de armazenamento. O cálculo da área de contribuição considerou a superfície da área que recebe as águas pluviais desconectadas adicionada à superfície da própria TC. 
Revista Latino-americana de

Ambiente Construído \& Sustentabilidade

ISSN 2675-7524 / V. 1, n. 1 (2020)

Tabela 1: TCs UFSCar e áreas utilizadas

\begin{tabular}{lccc}
\hline $\begin{array}{c}\text { Técnica } \\
\text { Compensatória }\end{array}$ & $\begin{array}{c}\text { Área ocupada pela TC } \\
\left(\mathbf{m}^{\mathbf{2}}\right) \text { - A }\end{array}$ & $\begin{array}{c}\text { Área de contribuição } \\
\left(\mathbf{m}^{\mathbf{2}} \mathbf{)}-\mathbf{B}\right.\end{array}$ & $\begin{array}{c}\text { Relação A/B } \\
(\mathbf{\%})\end{array}$ \\
\hline Plano I & 385 & 3386 & 11,4 \\
Plano II & 354 & 7701 & 4,6 \\
FVT & 570 & 3901 & 14,6 \\
Poço-Plano & 18 & 453 & 4,0 \\
Poço-Valeta & 3,8 & 152 & 2,5 \\
Poço I & 1,2 & 288 & 0,4 \\
Poço II & 1,2 & 182 & 0,6 \\
\hline
\end{tabular}

Fonte: LUCAS, 2011; ANGELINI SOBRINHA, 2012; TECEDOR, 2014; BAPTISTA, 2015; PEREIRA, 2016; FERREIRA, 2016; GOOGLE EARTH, 2019; elaborado pelo autor, 2019.

\section{CONCLUSÃO}

Após observação e análise, por meio das diferentes teses e dissertações sobre os diferentes aspectos das TCs UFSCar, pode-se considerar que houve significativa contribuição do ponto de vista hidrológico, ambiental e sanitário. Urbanisticamente, ganhou-se espaços livres qualificados, mesmo com restrita manutenção.

No decorrer dos anos, além de pesquisas decorrentes do dimensionamento hidrológico e do acompanhamento e observação empírica pelo G-HIDRO, não houve relatos ou reclamações juntos à Prefeitura do campus quanto ao acúmulo de água pluvial para além das 24 horas de cálculo, mesmo em ocasiões com elevado índice pluviométrico. Conclui-se que as TCS atendem às recomendações sanitárias e funções hidrológicas para o qual foi projetado.

Quanto ao tratamento paisagístico, houve perda da maior parte do projeto implantado, devido à manutenção não adequada e ao ataque, principalmente, de formigas, pela proximidade ao Cerrado. Após algumas semanas de sua implantação, descobriu-se a preferência da fauna local pelas espécies vegetais escolhidas, principalmente as floradas (PEREIRA, 2016). Entretanto, restaram algumas espécies de maior porte, como agaves e palmeiras.

O campus da UFSCar, como fragmento do espaço urbano, evidencia que, para implementação destas abordagens que favorecem escoamento superficial e a infiltração de águas pluviais, são requeridos espaços urbanos disponíveis (lotes, glebas, áreas verdes etc.), visto que seriam minimizados os sistemas de tubulações enterradas.

A análise de percentual ocupado pelas TCs UFSCar demonstrou que as áreas ocupadas pelo PI1 e FVT foram superestimadas, visto a eficácia de dispositivos de planos de infiltração com área ocupada próxima à 4 ou $5 \%$ da área de contribuição.

Se comparadas as taxas médias de permeabilidade exigidas pelos municípios ( $10 \%$ da área do lote) às porcentagens de áreas necessárias para a construção dos dispositivos, são suficientes. Porém, nas áreas permeáveis não há especificações quanto a exigência de TCs, que poderiam otimizar a capacidade de armazenamento e infiltração de águas pluviais.

Complementarmente, a possibilidade de multifuncionalidade da área da TC otimizaria os espaços de permeabilidade, proporcionando melhor aproveitamento de tais áreas, além de corroborar com a comprovação da possibilidade de implantação de dispositivos, inclusive em pequenas áreas.

A execução de TCs já é uma realidade nas cidades brasileiras, porém não se encontra 
destaques quanto à compatibilização destas e Planos de Uso do Solo, PDUs e até Planos de Drenagem. Tais estudos são objetos do mestrado do autor, que aborda a da compatibilização entre PDUs e espaços necessários para o manejo sustentável de águas pluviais.

Este artigo contribui para avaliação do uso das técnicas para a gestão pública a partir de estudos como estes, tendo em vista que a aplicação dos experimentos realizados em escala real comprovam a eficiência hidrológica e a possibilidade de integração paisagística e urbanística de Técnicas Compensatórias com objetivo de retenção e detenção das águas pluviais em ambiente urbano construído.

Ressalta-se, porém a importância de que tais abordagens alternativas e sustentáveis devem ser discutidas, principalmente, nos PDUs, de modo que suas aplicabilidades atinjam a cidade real e a função social e ambiental da destinação do solo urbano.

\section{REFERÊNCIAS}

ANGELINI SOBRINHA, L. A. Monitoramento e modelagem de um poço de infiltração de águas pluviais em escala real e com filtro na tampa. São Carlos: Universidade Federal de São Carlos, 2012. 149 p.

BAPTISTA, L. F. S. Aspectos Ambientais, Sanitários, Hidrológicos e Urbanísticos na Concepção e Aplicação do LID (Low Impact Development) em Microbacia na UFSCar. São Carlos: Universidade Federal de São Carlos, 2015. 171 p.

BAPTISTA, M. B.; NASCIMENTO, N. O.; BARRAUD, S. Técnicas Compensatórias em Drenagem Urbana. Porto Alegre: Associação Brasileira de Recursos Hídricos, 2011. 318 p.

BARROS, A. M. F. B.; CARVALHO, C. S.; MONTANDON, D. T. O Estatuto da Cidade comentado: Lei № 10. 257 de 10 de julho de 2001. In: CARVALHO, C. S.; ROSSBACH, A. O Estatuto da Cidade: comentado. São Paulo: Ministério das Cidades: Aliança das Cidades, 2010. Disponível em:

http://www.cidades.gov.br/images/stories/ArquivosSNPU/Biblioteca/PlanelamentoUrbano/EstatutoComentado_Po rtugues.pdf. Acesso em: 9 abr. 2019.

BUTLER, D.; DAVIES, J. W. Urban drainage. Londres: St. Edmundsbury Press, 2000. 489 p.

CAMBRIDGE CITY COUNCIL. Cambridge design and adoption guide: sustainable drainage. Cambridge: Environment and Planning Cambridge City Council, 2009. Disponível em: https://www.cambridge.gov.uk/media/5457/sudsdesign-and-adoption-guide.pdf. Acesso em: 06 set. 2019.

FELIPE, M. C. Avaliação da eficiência e modelagem matemática da remoção de material particulado em canal gramado integrante de técnica compensatória construída em escala real. São Carlos: Universidade Federal de São Carlos, 2014. 104 p.

FERNANDES, E. O Estatuto da Cidade e a ordem jurídico-urbanística. In: CARVALHO, C. S.; ROSSBACH, A. O Estatuto da Cidade: comentado. São Paulo: Ministério das Cidades: Aliança das Cidades, 2010. Disponível em: http://www.cidades.gov.br/images/stories/ArquivosSNPU/Biblioteca/PlanelamentoUrbano/EstatutoComentado_Po rtugues.pdf. Acesso em: 9 abr. 2019.

FERREIRA, T. S. Avaliação do comportamento hidrológico de poços de infiltração de águas pluviais sob diferentes concepções. São Carlos: Universidade Federal de São Carlos, 2016. 149 p.

INSTITUTO BRASILEIRO DE GEOGRAFIA E ESTATÍSTICA - IBGE. Sinopse do Censo Demográfico 2010. [S. I.], 2010. Disponível em:

https://ww2.ibge.gov.br/home/estatistica/populacao/censo2010/sinopse/sinopse_tab_brasil_zip.shtm. Acesso em: 25 mar. 2019.

JHA, A. K.; BLOCH, R.; LAMOND, J. Cidades e Inundações: um guia para a gestão integrada do risco de inundação urbana para o século XXI. Washington, D.C.: The World Bank, 2012. Disponível em:

http://mi.gov.br/pt/c/document_library/get_file?uuid=3c3b9a72-9358-415f-9efe-89fad4cbb381\&groupld=10157. 
Acesso em: 15 ago. 2019.

LUCAS, A. H. Monitoramento e modelagem de um sistema filtro-vala-trincheira de infiltração em escala real. São Carlos: Universidade Federal de São Carlos, 2011. $159 \mathrm{f}$.

MOTA, E. (coord.). Projeto técnico: calçadas acessíveis. [S. I.]: Soluções para Cidades, 2014. 22 p. Disponível em: http://solucoesparacidades.com.br/mobilidade/projeto-tecnico-calcadas-acessiveis/. Acesso em: 6 set. 2019.

OLIVEIRA, A. P. Avaliação da multifuncionalidade e de custos de técnicas compensatórias de drenagem na revitalização de áreas urbanas em Guarulhos, SP. São Carlos: Universidade Federal de São Carlos, 2018. 173 p.

PAIVA, S. B. Subprojeto LID/UFSCar. São Carlos: Universidade Federal de São Carlos, 2016. 9 p.

PARRA, G. G. Estudo comparativo dos efeitos dos espaços de circulação e permanência de pedestres (ECPP) sobre o manejo das águas de chuva. São Carlos: Universidade Federal de São Carlos, 2016. 120 p.

PEREIRA, T. R. D. S. Projeto paisagístico como instrumento de integração de técnicas compensatórias à paisagem urbana: Estudo de caso aplicado em planos de infiltração do campus da UFSCar. São Carlos: Universidade Federal de São Carlos, 2016. 127 p.

PREFEITURA MUNICIPAL DE MESQUITA (Brasil, Rio de Janeiro, Mesquita). Secretaria Municipal de Meio Ambiente e Urbanismo. Calçada melhor: manual prático para construção e manutenção de calçadas no município de Mesquita. Mesquita: Secretaria Municipal de Meio Ambiente e Urbanismo, 2018. 94 p. Disponível em:

http://www.mesquita.rj.gov.br/pmm/manual-de-acessibilidade-calcada-melhor.pdf. Acesso em: 6 set. 2019.

PRINCE GEORGE'S COUNTY. Low-Impact Development Design Strategies: an integrated design approach. Maryland: Department of Environmental Resource, 1999. Disponível em:

https://www.princegeorgescountymd.gov/1478/Design-Manuals. Acesso em: 28 mar. 2019.

REIS, R. P. A.; OLIVEIRA, L. H.; SALES, M. M. Sistemas de drenagem na fonte por poços de infiltração de águas pluviais. Ambiente Construído, Porto Alegre, v. 8, n. 2, p. 99-117, abr./jun. 2008.

RIGHETTO, A. M. (Coordenador). Manejo de Águas Pluviais Urbanas. Rio de Janeiro: ABES, 2009. Disponível em: https://www.finep.gov.br/images/apoio-e-financiamento/historico-de-programas/prosab/prosab5_tema_4.pdf. Acesso em: 14 ago. 2019.

SHINZATO, A. H. Avaliação da remoção de material particulado em canal raso gramado. São Carlos: Universidade Federal de São Carlos, 2015. 75 p.

SOUZA, V. G. A. S.; CABRAL, J. J. S. P.; COUTINHO, A. P.; SILVA, P. O. Construção de trincheira de infiltração aplicada como técnica compensatória em uma bacia urbana na cidade do Recife-PE. In: Encontro Nacional De Águas Urbanas, XII, 2018, Recife/PE. [...]. Recife: ABRH, 2018. Disponível em: https://s3-sa-east1.amazonaws.com/abrh/Eventos/Trabalhos/82/10313.pdf. Acesso em: 4 set. 2019.

TECEDOR, N. Monitoramento e modelagem hidrológica de plano de infiltração construído em escala real. São Carlos: Universidade Federal de São Carlos, 2014. 94 p.

TUCCI, C. E. M. Inundações Urbanas. In: Carlos E. M. Tucci; Rubem La Laina Porto; Mário T. de Barros. (Org.). Drenagem Urbana. Porto Alegre: Editora da Universidade (UFRGS) - ABRH Assoicação Brasileira de Recursos Hídricos, v. 1,1995. p. 15-36.

TUCCI, C. E. M. Gerenciamento da drenagem urbana. RBRH - Revista Brasileira de Recursos Hídricos, Porto Alegre, p. 5-27, jan./mar. 2002. Disponível em:

https://www.abrh.org.br/SGCv3/index.php?PUB=1\&ID=99\&SUMARIO=1583. Acesso em: 23 mar. 2019.

UNIVERSITY OF ARKANSAS COMMUNITY DESIGN CENTER. LID - Low Impact Development: a design manual for urban areas. Fayetteville: University of Arkansas Press, 2010. Disponível em: http://uacdc.uark.edu/work/lowimpact-development-a-design-manual-for-urban-areas. Acesso em: 24 mar. 2019.

URBONAS, B.; STAHRE, D. Stormwater: Best management practices and detention for water quality, drainage and CSO management. Englewood Cliffs: Prentice Hall, 1993. 449 p. 
VENTURA, K. S.; VAZ FILHO, P.; GONÇALVES, L. M. Gestão integrada de projetos sustentáveis em municípios de médio porte. In: ROSIN, J. A. R. G.; BENINI, S. M. Cidade Sustentável: um conceito em construção. Tupã/SP: ANAP, 2019. 